\title{
Uveal Melanoma Mimicking Advanced Coats' Disease in a Young Patient
}

\author{
Naina Gupta ${ }^{a}$ William Terrell ${ }^{a}$ Lynn Schoenfield ${ }^{a, b} \quad$ Claudia Kirsch $^{c}$ \\ Colleen M. Cebulla ${ }^{a}$ \\ ${ }^{a}$ Havener Eye Institute, Department of Ophthalmology and Visual Science, and ${ }^{\mathrm{b}}$ Department of Pathology, \\ The Ohio State University Wexner Medical Center, Columbus, Ohio, and ' Department of Radiology, North Shore \\ Long Island Jewish Health System, Hofstra Medical School, Manhasset, N.Y., USA
}

\section{Key Words}

Uveal melanoma · Necrotic choroidal melanoma $\cdot$ Coats' disease

\begin{abstract}
Background/Aims: To report a case and the unique histopathology of a necrotic uveal melanoma mimicking advanced Coats' disease in a young adult. Method: A 26-year-old male presented with a blind, painful eye, total exudative retinal detachment, and bulbous aneurysms consistent with Coats' disease. No masses were visualized on ultrasound or CT scan, and the patient underwent enucleation of the eye. Results: Histopathology of the involved eye confirmed a necrotic uveal melanoma with persistent spindle cells forming a collar around residual tumor vessels. Conclusion: Careful consideration is needed in approaching any patient with a blind, painful eye and opaque media, even in younger populations.
\end{abstract}

(c) 2015 S. Karger AG, Basel

\section{Introduction}

Occult ocular neoplasms have been discovered after enucleation [1,2] or evisceration [3] of blind, painful eyes and may present in unusual ways, particularly when ne- crotic [4-8]. Here, we present a case of necrotic, uveal melanoma with atypical presentation, mimicking advanced Coats' disease.

\section{Case Report}

This single case report was considered exempt from our Institutional Review Board. A 26-year-old incarcerated male, with a past medical history of hepatitis $\mathrm{C}$, presented to the emergency department complaining of 1 week of headache and a red, painful right eye (OD), associated with nausea and vomiting. He noted a 1 -year history of atraumatic, painless blindness OD. Visual acuity was 'no light perception' OD and 20/20 in the left eye (OS), with a relative afferent pupillary defect $\mathrm{OD}$ and intraocular pressures of $42 \mathrm{~mm} \mathrm{Hg}$ OD and $15 \mathrm{~mm} \mathrm{Hg}$ OS. Slit lamp examination OD showed extensive anterior chamber flare and florid iris neovascularization. A total exudative retinal detachment was visible near the lens (fig. 1a), with turbid, yellow subretinal fluid, small subretinal hemorrhage, and numerous bulbous aneurysms within the retinal vasculature (fig. 1b). Gonioscopy revealed neovascularization of the iris and angle, with angle closure OD. OS examination was normal. B scan, though limited due to the patient's pain, revealed a mobile retinal detachment with shifting subretinal opacities and no solid mass (fig. 1c). CT with contrast showed diffusely increased attenuation through the entire right globe, suggestive of hemorrhagic and/or proteinaceous products (fig. 1d); no mass was visualized. The findings were consistent with stage 5 Coats' disease [9].

\section{KARGER}

E-Mail karger@karger.com

www.karger.com/oop
(C) 2015 S. Karger AG, Basel

2296-4681/15/0023-0140\$39.50/0
Colleen M. Cebulla, MD, PhD

Department of Ophthalmology and Visual Science The Ohio State University Wexner Medical Center 915 Olentangy River Road, Suite 5000, Columbus, OH 43212 (USA) E-Mail colleen.cebulla@ osumc.edu 

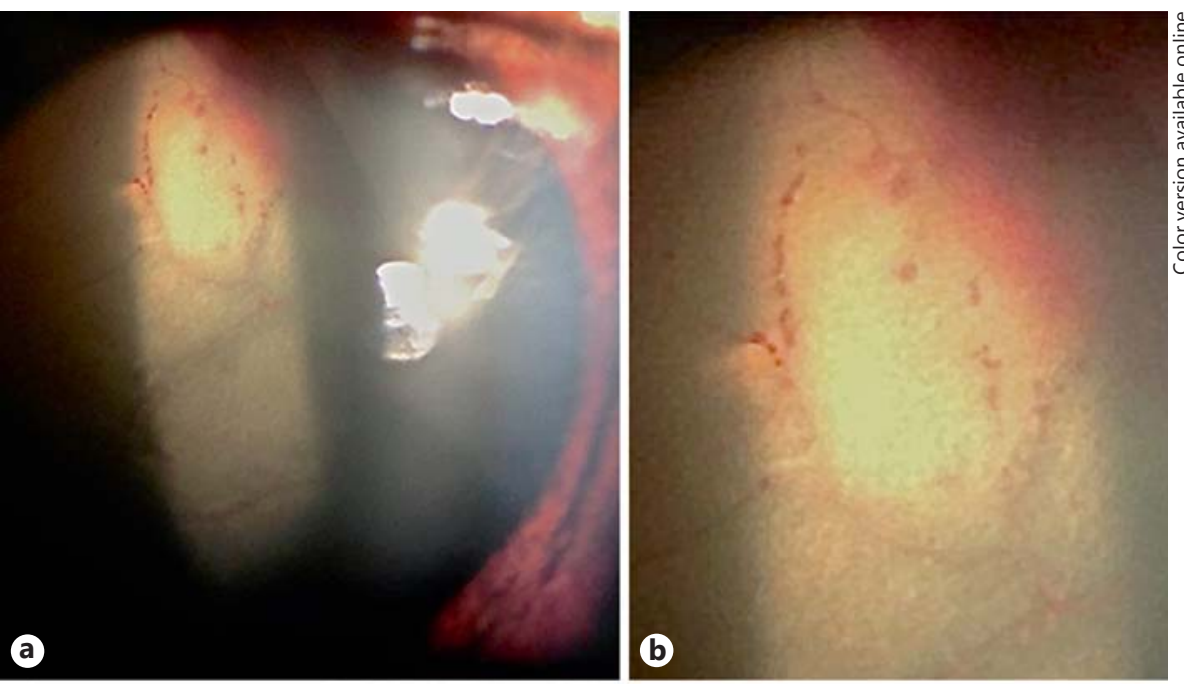

Fig. 1. Images of the right eye. a External photograph depicting total exudative retinal detachment with the retina visible against the posterior lens. b Magnified view, with a bulbous aneurysm of the retinal vasculature. c B scan $(10 \mathrm{mHz})$ with medium to high reflectivity of the subretinal material. The dynamic view identified a partially mobile exudative retinal detachment with no identifiable solid mass. d CT orbits with contrast identifying diffusely increased attenuation throughout the entire globe, suggestive of hemorrhagic or proteinaceous products. No solid mass was identified.
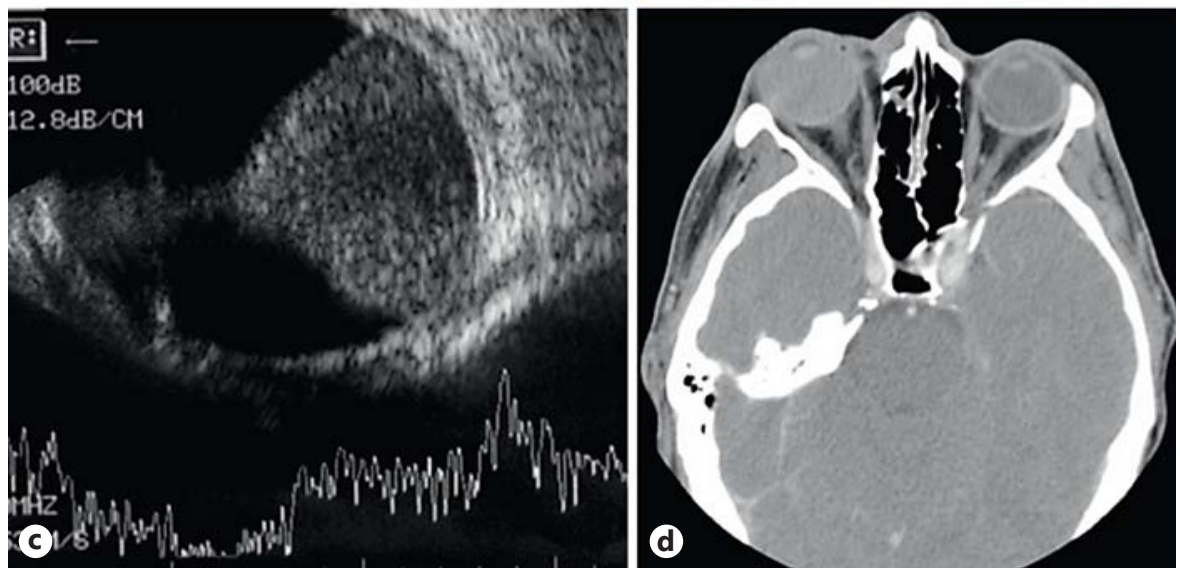

Despite medical therapy, the patient's pain was uncontrolled. He underwent an uncomplicated enucleation OD with no gross external abnormalities of the globe.

Histopathology (fig. 2) showed an extensively necrotic (75\%) choroidal melanoma in the temporal posterior globe, which was obscured by the extensive intraocular proteinaceous fluid. It spared the ciliary body and iris, and the anterior edge was $10 \mathrm{~mm}$ from the limbus and $2 \mathrm{~mm}$ from the optic nerve. Its largest basal diameter was $14 \mathrm{~mm}$, and its height was $7 \mathrm{~mm}$ (pT3a). The melanoma was predominantly spindle cell type (with $<10 \%$ epithelioid cells). There was no extension into the sclera, nor was there vascular invasion. Necrotizing scleritis was present. Immunohistochemical stains for both S-100 and melan A were positive, consistent with the diagnosis of melanoma. Similar to necrotic retinoblastomas, the melanoma consisted of large dilated vessels surrounded by a collar of tumor cells, 20-30 cells thick, with intervening necrosis.

The patient underwent a metastatic workup including an analysis of the complete blood count and lactate dehydrogenase, a comprehensive metabolic panel, a CT of the chest/abdomen/pelvis, and brain MRI. Chest CT revealed right hilar lymphadenopathy, with transbronchial biopsy showing lymphocyte aggregates without metastasis. All other testing was normal.

Melanoma Mimicking Advanced Coats' Disease

\section{Discussion}

Choroidal melanomas are rare in young adults [6], and spontaneous necrosis is similarly rare [7]. This patient's presentation in particular is unique, with its extensive necrosis, similarity to advanced Coats' disease, lack of enhancing mass on imaging, and unusual histopathology. The average presenting age of uveal melanoma is 55 , with previous studies showing them to be uncommon in younger individuals [6]. Histologically, the globe was filled with proteinaceous fluid, obscuring a necrotic melanoma in the posterior globe. The predominant spindle cell morphology is not typical of prior reported necrotic melanomas [4]. Frasier and Font [4] found that only $23 \%$ of uveal melanomas associated with inflammation were predominantly spindle cell type; most tumors were listed as having an epithelioid, mixed, or 'necrotic' cell type. The spontaneous necrosis of uveal melanomas is thought to develop due to the melano- 
Fig. 2. Histology of the enucleated right eye. a Whole mount photograph of the globe showing proteinaceous fluid obscuring the melanoma. H\&E. b Tumor cell aggregates surrounding blood vessels with intervening necrosis. H\&E. $\times 100$. c Highpower view of the viable melanoma with mostly spindle cell morphology. $\mathrm{H} \& \mathrm{E}$. $\times 400$. d Immunohistochemical stain for melan A showing positive staining in the viable perivascular melanoma cells, most of which are not pigmented. $\times 200$.
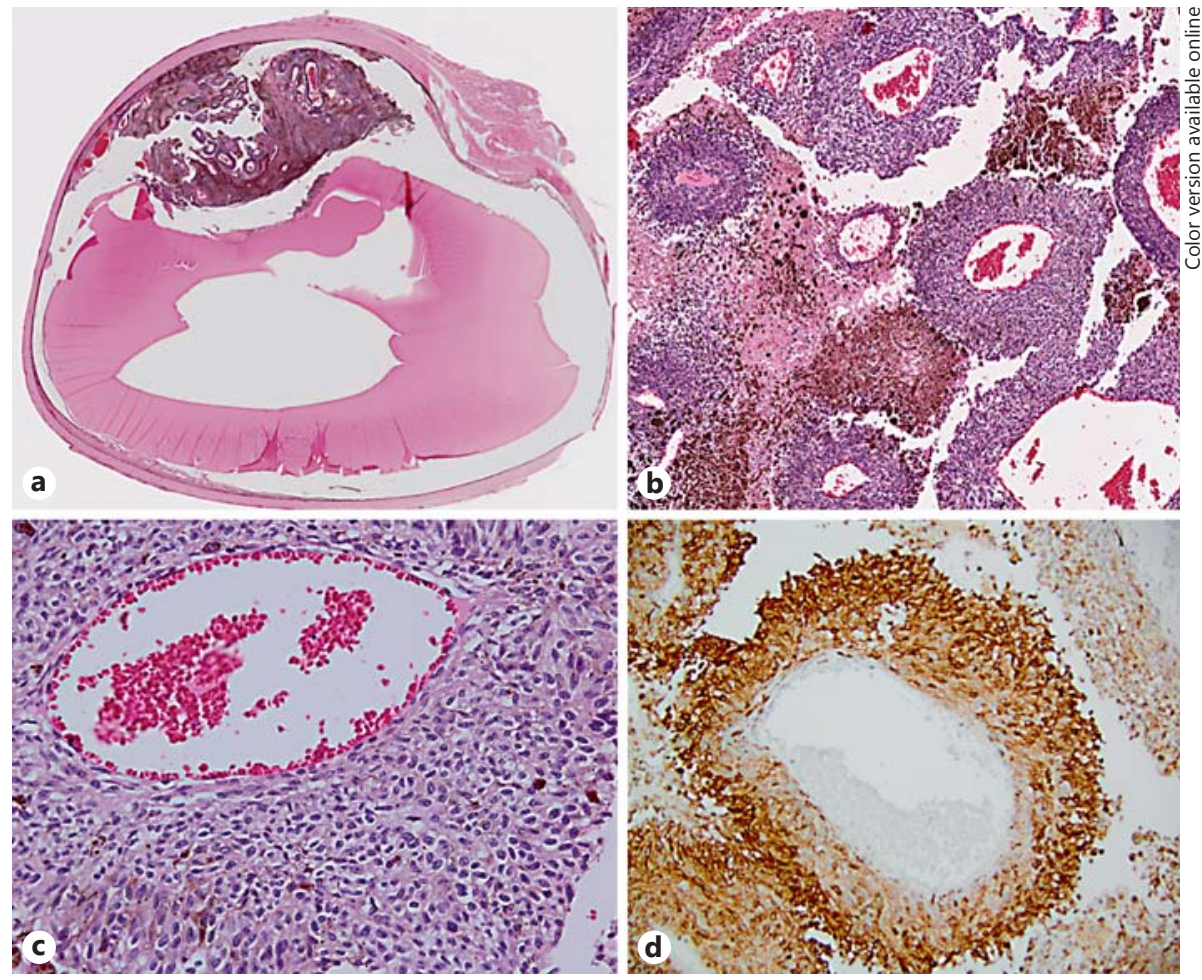

ma outgrowing its blood supply centrally in a watershed area [10]. In this case, the residual viable tumor persisted along prominent tumor vessels. Like many retinoblastomas, it consisted of large dilated vessels surrounded by a collar of melanoma cells, which were $20-30$ cells thick, with intervening necrosis.

An enucleation was performed rather than evisceration due to the inability to fully evaluate the posterior pole. While computed tomography (CT) is often the imaging modality of choice in the acute setting, increased attenuation from blood products, melanin, or proteinaceous material associated with a tumor can mask the iodinated contrast enhancement of the lesion, as has been reported with brain tumors; newer CT techniques such as dual-energy CT scanning are being developed to try to delineate tumoral enhancement that can be masked by hemorrhage [11]. MRI may also be limited by paramagnetic effects that can cause variable $\mathrm{T} 1$ and T2 signals [12]. Previous reports have been published describing the evisceration of occult melanomas in blind painful eyes [1-3]. The incidence of evisceration of occult melanomas is likely underreported.

In conclusion, an occult necrotic uveal melanoma must be considered in inflamed eyes with exudative ret- inal detachments, even in young patients. This case highlights the importance of enucleation rather than evisceration in blind painful eyes with opaque media and the potential limitations of modern imaging to detect these lesions.

\section{Acknowledgments}

Supported by the National Eye Institute of the National Institutes of Health under Award Number K08EY022672. Additional funds were provided by the Ohio Lions Eye Research Foundation and the Patti Blow Fund.

\section{Statement of Ethics}

This case report adheres to the tenants of the Declaration of Helsinki.

\section{Disclosure Statement} close.

The authors of this article have no conflicts of interest to dis- 


\section{References}

1 Char DH, Cole TB, Crawford JB: Management of occult necrotic melanomas. JAMA Ophthalmol 2013;131:1067-1069.

2 Makley TA Jr, Teed RW: Unsuspected intraocular malignant melanomas. AMA Arch Ophthalmol 1958;60:475-478.

3 Eagle RC Jr, Grossniklaus HE, Syet NA, Hogan RN, Lloyd WC III, Foldber R: Inadvertent evisceration of eyes containing uveal melanoma. Arch Ophthalmol 2009;127:141-145.

4 Fraser DJ, Font RL: Ocular inflammation and hemorrhage as initial manifestations of uveal malignant melanoma. Arch Ophthalmol 1979;97:1311-1314.

5 Blasi MA, Giammaria D, Balestrazzi E: Necrotic uveal melanoma with orbital inflammation. Eur J Ophthalmol 2006;16:647-650.
6 Shields C, Menduke H: Uveal melanoma in teenagers and children. Ophthalmology 1991; 98:1662-1666.

7 Moshari A, Cheeseman E, McLean I: Totally necrotic choroidal and ciliary body melanomas: associations with prognosis, episcleritis, and scleritis. Am J Ophthalmol 2001;131: 232-236.

8 Samuels B: Anatomic and clinical manifestations of necrosis in eighty-four cases of choroidal sarcoma. Arch Ophthalmol 1934;11: 998-1027.
9 Haik BG: Advanced Coats' disease. Trans Am Ophthalmol Soc 1991;89:371-476.

10 Thareja S, Rashid A, Grossniklaus HE: Spontaneous necrosis of choroidal melanoma. Ocul Oncol Pathol 2015;1:63-69.

11 Kim SJ, Lim HK, Lee HY, Choi CG, Lee DH, Suh DC, Kim SM, Kim JK, Krauss B: Dualenergy CT in the evaluation of intracerebral hemorrhage of unknown origin: differentiation between tumor bleeding and pure hemorrhage. AJNR Am J Neuroradiol 2012;33: 865-872.

12 Tong KA, Oborn AG, Mamalis N, Harrie RP, Call NB: Radiologic-pathologic correlation: ocular melanoma. AJNR Am J Neuroradiol 1993;14:1359-1365. 